\title{
Solitary splenic metastasis in a case of treated cervical cancer: a case report
}

\author{
Shetty Theertha Shankar ${ }^{1 *}$, Mangesh Panse ${ }^{2}$, Arjun Goel ${ }^{2}$
}

\begin{abstract}
${ }^{1}$ Department of Gynaecology, Galaxy Care Multispeciality Hospital Pvt. Ltd., Pune, Maharashtra, India
${ }^{2}$ Department of Surgery, Galaxy Care Multispeciality Hospital Pvt. Ltd., Pune, Maharashtra, India
\end{abstract}

Received: 17 February 2020

Revised: 20 March 2020

Accepted: 27 March 2020

\section{*Correspondence:}

Dr. Shetty Theertha Shankar,

E-mail: shettytheerthas@gmail.com

Copyright: (C) the author(s), publisher and licensee Medip Academy. This is an open-access article distributed under the terms of the Creative Commons Attribution Non-Commercial License, which permits unrestricted non-commercial use, distribution, and reproduction in any medium, provided the original work is properly cited.

\begin{abstract}
Cervical cancer is the second most common cancer among women worldwide and metastasis to the spleen is a rare entity, with only few cases being reported. The present case of a 55-year-old patient diagnosed with a splenic lesion 3 years following completion of chemotherapy combined with radiotherapy for advanced cervical cancer. The patient underwent diagnostic laparoscopy with splenectomy. The histopathological studies confirmed the presence of a metastatic squamous cell carcinoma (in a known case of treated cervical cancer). At one-year follow-up after splenectomy, the patient was free of any recurrent disease. Owing to its rarity and scant data available, detailed workup should be done whenever a solitary lesion in the spleen is detected on follow-up since splenectomy is the apt management which is instrumental in preventing further complications and improves the survival rates.
\end{abstract}

Keywords: Carcinoma, Cervix, Metastasis, Solitary

\section{INTRODUCTION}

Cervical cancer is the second most common cancer among women worldwide and is also the most common cause of cancer deaths in developing countries. ${ }^{1}$ A total 15 to $61 \%$ women with cervical malignancy develop distant metastases within first two years of completing treatment. $^{2}$

Cervical cancer spreads regionally by direct extension to adjacent structures or by lymphatic dissemination to regional nodes and rarely through hematogenous route to distant organs. ${ }^{3}$ Common site of distant metastasis includes lung, liver, and bones para-aortic nodes, the abdominal cavity and supra-clavicular nodes. ${ }^{4,5}$

In rare instances, solitary metastases have been reported, thereby making the patient a perfect candidate for solitary metastatectomy. ${ }^{6}$
Splenic metastasis from cervical cancer is very rare. ${ }^{7}$

This case hereby presents a case of a 55-year-old woman with a history of cervical cancer with metastasis to the spleen.

\section{CASE REPORT}

A 55-year-old P2L2D1 postmenopausal woman came to the outpatient department with complaints of on and off episodes of pain abdomen, nausea and vomiting since 4 months which had aggravated since 3 days.

She was evaluated outside 3 years back for complaints of postmenopausal bleeding for two months.

On per vaginal examination, a bulky cervix which bled on touch with no free space between the bladder and the cervix was noted. 
MRI pelvis was suggestive of a large lobulated cervical mass measuring $5.3 \times 4.8 \times 4.7 \mathrm{~cm}$ invading the lower myometrium up to cervico-vaginal junction.

Cervical biopsy showed moderately differentiated squamous cell carcinoma.

Diagnostic laparoscopy was done and intra-operatively, bladder was found to be densely adherent to the uterus and isthmus and was diagnosed to be stage IV A carcinoma cervix.

She was treated with concurrent chemotherapy using once weekly cisplatin $30 \mathrm{mg} / \mathrm{m}^{2}$ for 4 cycles along with external radiotherapy on linear accelerator, 50 Gy in 25 fractions in 5 weeks and three sittings of intra-cavitary radiotherapy of $7 \mathrm{~Gy}$ each.

She was declared disease free after completion of treatment and was on regular surveillance.

PET CT scan 3 years later revealed no obvious FDG avid lesion seen in the uterine cervix, no enlarged pelvic or retroperitoneal nodes.

FDG avid hypodense lesion measuring $2.1 \times 3.7 \mathrm{~cm}$ was seen in the spleen, HPE correlation was suggested.

CT guided Biopsy was taken from the splenic mass. Histopathology was suggestive of metastatic squamous cell carcinoma (in a known case of carcinoma cervix).

\section{Intraoperative findings}

Diagnostic laparoscopy was done which revealed a spleen with subcapsular nodule and a splenectomy was performed. No other metastatic deposit or nodule was seen elsewhere. Uterus and parametria were normal.

Post-operative course was uneventful and she was discharged on the third post-operative day.

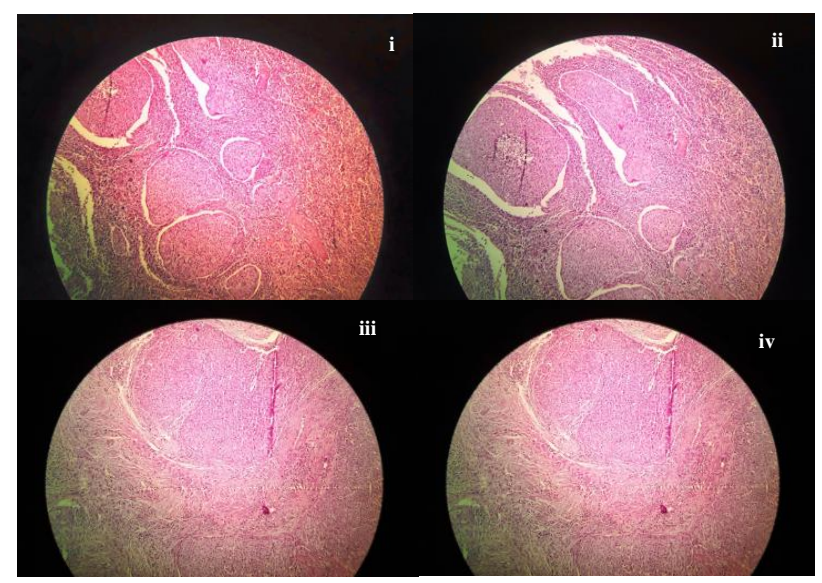

Figure 1: (i, ii, iii, iv) Histopathological picture of moderately differentiated squamous cell carcinoma with no extension beyond splenic capsule.

\section{Histopathology}

Histopathology revealed metastatic moderately differentiated squamous cell carcinoma grade II with no extension beyond splenic capsule (Figure 1; i, ii, iii, iv).

\section{DISCUSSION}

Carcinoma cervix is the most common malignancy in Indian women, having an incidence of 19-44 per 100,000 women and is the most common cancer cause of death among women in the developing countries..$^{1,4}$

Premalignant as well as early malignant cervical cancers are usually asymptomatic and are detected during screening. But, advanced-stage cervical cancer almost always presents with abnormal vaginal bleeding or foul-smelling discharge. ${ }^{8}$

Cervical cancer, although potentially detectable with available screening methods, continues to be an important cause of morbidity and gynecological cancer deaths, where many patients present with advanced disease at the time of presentation. ${ }^{3}$

In many western countries screening programmes have reduced the incidence of invasive disease by permitting an early diagnosis. ${ }^{2}$

Several factors contribute to distant metastases which include advanced stage, endometrial extension and local failure. ${ }^{5}$

Malignancies known to metastasize frequently are melanoma, kidney, lung, thyroid cancer, lymphoma, and leukaemia and colon cancer. ${ }^{8}$

Distant metastasis from cervix cancer to unusual sites such as the breast, skeletal muscle, duodenum, femur, skin or spleen are extremely rare., , $4,5,8,9^{-}$

Knowledge of cervical cancer has increased greatly regarding the etiological agent human papillomavirus, pathogenesis and its metastatic pathways.

But the cancer still poses challenges for the clinicians owing to its unusual presentations. These cases highlight the significance of combining history, imaging, and histology together to reach a diagnosis for an accurate management. ${ }^{10}$

A case was reported by Dixit $\mathbf{J}$ et al, which where the patient had undergone radical hysterectomy followed by radiation therapy and chemotherapy.

Histopathologically, the tumor was stage IB1.

Following an asymptomatic period of 17 months, she developed fever and anorexia. 
$\mathrm{PET} / \mathrm{CT}$ showed recurrence in the spleen and in the mesentery within pelvis. Histology of spleen and mesenteric lesion showed metastatic poorly differentiated carcinoma.

Immunohistochemistry confirmed the primary to be squamous cell carcinoma of cervix associated with highrisk $\mathrm{HPV}^{7}$

Metastases to the spleen are rare and are mostly detected on autopsy. Possible routes of metastasis to spleen include the splenic artery, splenic vein and lymphatics. ${ }^{11}$

Several proposed theories given for decreased incidence of metastasis to the spleen include acute angle at the origin of splenic artery and its tortuosity, lack of afferent lymphatics to the splenic parenchyma, splenic capsule which may act as an effective barrier, rhythmic contractions of the spleen, immunity and possibly antineoplastic properties of the splenic tissue. ${ }^{12}$

Solitary splenic metastasis often causes a diagnostic dilemma with primary tumors of spleen. Vague presenting symptoms include pain and fullness of abdomen, abdominal mass or rarely may present with rupture as an emergency.

Splenectomy is an apt treatment which can confirm the histopathology and avoid complications including splenic rupture, splenic vein thrombosis and painful splenomegaly, which prevent splenic metastasis from being a source for further metastatic disease. ${ }^{13}$ Carlson et al, reported in their review that incidence of distant metastasis of 2200 cases of squamous cell carcinoma of the cervix was $15.3 \% .^{14}$

According to a case report by Dixit et al, which reported splenic metastasis at 17 months after completion of the oncological treatment for squamous cell cervical cancer, only 11 cases had been published before, with their case being the $12^{\text {th }}$ reported ever. ${ }^{6}$

Most of the literature available until today focuses on scattered case reports, as well as autopsy series between 20-80 years ago. Lack of information is thought to be due to selection bias and an overall decrease in the number of subjects undergoing autopsy. ${ }^{15}$

Advances in chemotherapy, irradiation, and surgical treatment have resulted in better control of disease and longer survival and has also led to decreased incidences of distant metastases. ${ }^{16}$

\section{CONCLUSION}

Metastasis of cervical cancer to the spleen alone is a rare occurrence. However, the possibility cannot be ruled out while managing patients with a past history of cervical cancer.
Owing to its rarity and scant data available, detailed workup should be done whenever a solitary lesion in the spleen is detected on follow-up since splenectomy is the apt management which is instrumental in preventing further complications and improves the survival rates.

Hence, surveillance following treatment of cervical cancer is of paramount importance for early detection and management of metastatic lesions.

\section{Funding: No funding sources \\ Conflict of interest: None declared \\ Ethical approval: Not required}

\section{REFERENCES}

1. Bhandari V, Kausar M, Naik A, Batra M. Unusual metastasis from carcinoma cervix. The J Obstet Gynecol India. 2016;66(5):358-62.

2. Bellefqih S, Mezouri I, Khalil J, DiakitÃ A, Khannoussi BE, Kebdan T. Skin metastasis of cervical cancer: About an unusual case. J Clin Case Rep. 2013;3(284):2

3. Senthil R, Mohapatra RK, Srinivas S, Sampath MK, Sundaraiya S. Unusual presentation of metastatic carcinoma cervix with clinically silent primary identified by $18 \mathrm{~F}$-flouro deoxy glucose positron emission tomography/computed tomography. Indian J Nucl Med. 2016;31:134-7.

4. Nag P, Bhandari V, Kausar M, Goyal H. Duodenal metastasis from carcinoma cervix: An unusual presentation and review of literature. Clin Cancer Invest J. 2016;5:166-8.

5. Thakur P, Verma V, Fotedar V, Sharma M. Femur metastasis: a rare metastatic site in carcinoma cervix. J Case Reports. 2018;8(2):95-7.

6. Bacalbasa N, Balescu I, Marcu M, Oprescu DN, Anca AF. Solitary splenic metastasis after surgicallytreated cervical cancer-a case report and literature review. Anticancer Res. 2017;37(5):2615-8.

7. Dixit J, Mohammed N, Shetty P. Splenic metastasis from cancer of uterine cervix-a rare case. Indian $\mathbf{J}$ Surg Oncol. 2016;7(4):479-83.

8. Kausar M, Ladia DD, Mutneja A, Bhandari V. Unusual skeletal muscle metastasis from carcinoma cervix. J Cancer Metastasis Treat. 2016;2:67-9.

9. Yetmen Ö, Öksüz DÇ, Demirkıran F, Özgüroğlu M, Calay Z, Atkovar G, et al. Unusual presentation of cervical carcinoma metastasis to the breast: a case report and review of the literature. Meme Sagligi Dergisi/J Breast Health. 2012;8(2):92-6.

10. Pandey D, Shetty J, Sambhaji C, Saxena PU, Mishra D, Chawla A. Cervical Cancer as a silent killer: A rare case report with review of literature. J Can Res Ther. 2015;11:653.

11. Pang LC. Solitary recurrent metastasis of squamous cell carcinoma of the uterine cervix in the spleen: case report. South Med J. 2004;97(3):301-4. 
12. Koh YS, Kim JC, Cho CK. Splenectomy for solitary splenic metastasis of ovarian cancer. BMC Cancer. 2004;4:96

13. Piura B, Rabinovich A, Apel-Sarid L, Shacol-Levy R. Splenic metastasis from endometrial carcinoma: report of a case and review of literature. Arch Gynecol Obstet. 2009;280(6):1001-6.

14. Gupta TT. Splenic metastases from cervical carcinoma: a case report. International J Gynecol Cancer. 2006;16(2):911-4.

15. Applebaum M, Schulz B. Isolated splenic metastasis in a patient with squamous cell carcinoma of the cervix. Applied Radiol. 2017:24-5.
16. Taga S, Sawada M, Nagai A. Splenic metastasis of squamous cell carcinoma of the uterine cervix: a case report and review of the literature. Case Reports Obstet Gynecol. 2014;2014:1-4.

Cite this article as: Shankar ST, Panse M, Goel A. Solitary splenic metastasis in a case of treated cervical cancer: a case report. Int J Reprod Contracept Obstet Gynecol 2020;9:2211-4. 